\title{
O Processo de (Sub) Desenvolvimento Brasileiro: uma abordagem histórico-estruturalista
}

\author{
Daniel Claudy Da Silveira ${ }^{1}$ \\ Berenice Beatriz Rossner Wbatuba² \\ Cidonea Machado Deponti ${ }^{3}$
}

\begin{abstract}
Resumo
$O$ estudo analisa a incipiência do desenvolvimento da América Latina na segunda metade do século $X X$, que determinaram trajetórias distintas de desenvolvimento. Para diagnosticar o porquê de sociedades desenvolvidas e não desenvolvidas, foram criados vários modelos analíticos de desenvolvimento. Trata-se de uma revisão de literatura, de carácter descritivo-analítico em que são analisados diferentes pensadores, que contribuíram para explicação do fenômeno ocorrido na América Latina, particularmente no Brasil, e suas determinantes no processo de desenvolvimento, ou melhor, subdesenvolvimento. Consideram-se as especificidades estruturais, que partiram de um conceito de desenvolvimento baseado em modelo agroexportador para um processo de substituição de importações, com forte estímulo à indústria nascente e a demanda interna. Concluiu-se que os autores da teoria histórica-estruturalista, da qual emerge a CEPAL, lideraram a maior corrente de pensamento desenvolvimentista latino-americana, sendo os precursores do arcabouço teórico sobre as dinâmicas do desenvolvimento econômico e que formaram a base teórica para o desenvolvimento de políticas públicas do Estado. Esta base teórica teve como visão à superação dos entraves, principalmente de cunhos estruturais e sociais, e, assim estimularam à promulgação do desenvolvimento econômico.
\end{abstract}

Palavras-chave: América Latina. Brasil. Desenvolvimento. Subdesenvolvimento. Especificidades Estruturais.

\begin{abstract}
The study analyzes the incipience of Latin American development in the second half of the twentieth century, which determined distinct development paths. To diagnose the reason why developed and undeveloped societies, several analytical models of development have been created. Different thinkers are analyzed, which contributed to explain the phenomenon that occurred in Latin America, particularly in Brazil, and its determinants in the process of development, or rather, underdevelopment. Structural specificities are considered, starting from a concept of development based on an agro-export model for a process of import substitution, with strong stimulus to nascent industry and domestic demand. It was concluded that the authors of the historical-structuralist theory, from which CEPAL emerged, led the mainstream of Latin American developmental thought, being the forerunners of the theoretical framework on the dynamics of economic development and that formed the theoretical basis for development of public policies of the State. This theoretical basis had as its vision the overcoming of obstacles, mainly structural and social, and thus stimulated the promulgation of economic development.
\end{abstract}

Keywords: Latin America. Brazil. Development. Underdevelopment. Structural Specifics.

\section{Introdução}

A economia latino-americana, e particularmente brasileira, sofreu grandes transformações no decorrer do século XX. Até então, ela tinha uma base agroexportadora, e seu dinamismo estava estritamente vinculado ao comportamento da demanda externa. A grande depressão de 1929, que reduziu sensivelmente o comércio internacional, propiciou ao Brasil, o desenvolvimento de um processo de substituição de importações (PSI) através do incentivo à indústria nascente. Concomitantemente, a Revolução de 1930 representou no cenário político a

1 Doutor em Desenvolvimento Regional (PPGDR/UNISC). Professor do Curso de Ciências Econômicas do Departamento de Ciências Administrativas, Contábeis, Econômicas e da Comunicação (DACEC/UNIJUí). daniel.silveira@unijui.edu.br.

2 Doutora em Desenvolvimento Regional (PPGDR/UNISC). Professora do Programa de Pós-Graduação em Gestão Estratégica de Organizações (PPGGEO) da Universidade Regional Integrada do Alto Uruguai e das Missões (URI)Campus de Santo Ângelo/RS. bwbatuba@santoangelo.uri.br.

3 Doutora em Desenvolvimento Rural (PPGDR/UFRGS). Professora do Programa de Pós-Graduação em Desenvolvimento Regional (PPGDR/UNISC). cidonea@unisc.br. 
ascensão das camadas urbanas altas e médias e de outros segmentos da sociedade. Esses setores, identificados com a acumulação urbano-industrial, passaram gradativamente a ganhar mais espaço político e viram suas teses desenvolvimentistas serem respaldadas por medidas de política econômica que dinamizaram o crescimento industrial.

Paralelamente a esse processo de desenvolvimento econômico iniciado nos anos 1930, e que também se verificava com distintos graus de intensidade em outras partes do mundo, acabou propiciando uma nova gama de pensadores preocupados em explicar as relações entre agricultura e desenvolvimento em países que tinham ingressado tardiamente no capitalismo industrial.

Neste sentido, serão consideradas as teses ou pensadores mais representativos, como Prebisch, Furtado, Lewis, Tavares e Cardoso \& Faletto, que diagnosticaram de forma mais equitativa e aprofundada a realidade em questão, através da abordagem histórica-estruturalista, em relação ao desenvolvimento da América Latina no século XX e as suas principais ideias apresentadas para o período.

Embora haja diferentes métodos para organizar a exposição dessas teses e análises, pelo menos dois deles merecem destaque. Um primeiro recorte metodológico poderia ser feito classificando-se os autores das teses de acordo com seus marcos teóricos e conceituais individuais. Assim, ter-se-iam dois grandes grupos. Num deles, estariam os autores que, em seus esquemas analíticos, utilizam-se de variáveis estritamente econômicas (produtividade marginal, alocação dos fatores, etc...), isto é, pensadores identificados com a corrente da economia neoclássica ("mainstream economics"). E, no outro grupo, aqueles autores que resgatam o caráter social da análise econômica, ou seja, consideram em seus esquemas explicativos o econômico latu sensu, que inclui outras variáveis, como o processo histórico, a demografia, a estrutura social, a distribuição da renda, entre outros (estruturalismo). Na falta de uma qualificação mais adequada, esses autores podem ser vinculados à corrente da economia política ou histórico-estrutural (CASTRO, 1990, p. 199).

Portanto, este trabalho traz na primeira seção a discussão sobre o processo de desenvolvimento (subdesenvolvimento), com delimitação das teorias e pensadores do tema com base na CEPAL (Comissão Econômica para o Desenvolvimento da América Latina e Caribe). Na seção seguinte, discute-se a evolução do processo de desenvolvimento brasileiro, de acordo com suas especificidades e seu processo de industrialização e, consequentemente, a teoria da dependência da América Latina. Na parte final, há uma breve contextualização sobre tal processo de desenvolvimento e seus principais fundamentos que levaram a realidade em questão.

\section{0 desenvolvimento versus subdesenvolvimento}

$\mathrm{Na}$ incursão de diagnosticar o porquê de sociedades desenvolvidas e não desenvolvidas, foram criados vários modelos na busca do real problema dos países não desenvolvidos, basicamente os latino-americanos. A preocupação com tal realidade surgiu primordialmente na Europa Ocidental e nos Estados Unidos, após as décadas de 1930 e 1940. 
Neste contexto, Prebisch surge como o pai da teoria estruturalista na década de 1950, sendo igualmente o precursor da CEPAL. Sua tese argumenta que as distorções dos mercados internacionais são de algum modo desconsideradas, ou seja, há uma tendência a diminuição nas relações de trocas entre os países periféricos (subdesenvolvidos) e centrais (desenvolvidos). Assim, inicia a análise a partir do fato de que os países desenvolvidos são basicamente industrializados, produzindo produtos manufaturados, enquanto que os países subdesenvolvidos têm sua economia baseada na produção de bens primários de exportação, sendo vocacionados a produção de produtos agrícolas, que é o caso brasileiro.

Não obstante a isso, incipientemente em relação ao caso brasileiro, é necessário que se delimite os conceitos de desenvolvimento e subdesenvolvimento. Para tal, são usadas as definições de Furtado apud Agarwala e Singh (2010), em que se reitera que o processo de desenvolvimento se realiza através de novas combinações dos fatores existentes ao nível da técnica conhecida e, através da introdução de inovações técnicas. Conforme a distinção, os países desenvolvidos são aquelas regiões em que não havendo desocupação de fatores, só é possível aumentar a produtividade (a renda per capita) introduzindo novas técnicas/inovações. Por outro lado, as regiões subdesenvolvidas são aquelas em que a produtividade aumenta ou poderia aumentar por meio da implantação da técnica já existente.

Ainda de acordo com Furtado apud Agarwala e Singh (2010), o crescimento econômico para os países desenvolvidos é o problema de acumulação de novos conhecimentos científicos e de progressos na aplicação desses conhecimentos, e para os países subdesenvolvidos, é um processo de assimilação da técnica, pois numa região subdesenvolvida sempre existe alguma deficiência na utilização dos fatores de produção. Essa deficiência, não resulta necessariamente de má combinação dos fatores existentes, sendo esta, mais comumente ser resultante da escassez do fator capital, isto é, desperdiça-se um fator (mão-de-obra) porque o outro é insuficiente (capital).

Sendo assim, o estudo irá deter-se ao conceito de subdesenvolvimento, que perpassa sob forma intrínseca à realidade dos países latino-americanos, e por sua vez o Brasil. Para que compreender os problemas do subdesenvolvimento enfrentados pelo país, será considerada a obra de Raúl Prebisch (1950), "O desenvolvimento da América Latina e seus principais problemas".

Prebisch (1950, p. 47), acerca dos problemas das economias latino-americanas, dentre elas o Brasil, relaciona "[...] como parte da periferia da economia mundial, o papel específico de produzir alimentos e matérias-primas para os grandes centros industriais, ou seja, os países desenvolvidos, ditos capitalistas".

As grandes vantagens do desenvolvimento da produtividade não chegaram à periferia em medida comparável ao que lograram desfrutar as populações dos grandes países. Daí as diferenças tão acentuadas entre os níveis de vida das massas nestes e naquela, e as notórias discrepâncias entre suas respectivas forças de capitalização, uma vez que a margem de poupança depende, primordialmente, do aumento da produtividade. Existe, portanto, manifesto desequilíbrio, e qualquer que seja sua explicação ou a maneira de justificá-lo, trata-se de um fato certo, que destrói a premissa básica do esquema da divisão internacional do trabalho. Daí o 
significado fundamental da industrialização para os países novos. Ela não é um fim em si mesmo, mas o único meio de que se dispõe para captar uma parte do fruto do progresso técnico e elevar progressivamente o nível de vida das massas (PREBISCH, 1950).

O ponto de partida da análise de Prebisch (1950) foi à crítica a teoria das vantagens comparativas de David Ricardo, segundo o qual os países deveriam especializar-se na produção daqueles produtos para os quais apresentassem vantagens comparativas de custos.

O Brasil produziria alimentos e matérias primas para a exportação e importaria produtos manufaturados. A ideia era a de que o progresso técnico gerado nos países desenvolvidos (centrais), incorporado nas importações, difundir-se-ia nos países subdesenvolvidos (periféricos), por meio de redução dos preços dos produtos manufaturados importados.

Mas, no entanto, ao mesmo tempo, a menor incorporação de tecnologia na produção primária e a maior demanda dos países centrais, em virtude do crescimento de sua renda, elevariam os preços dos produtos primários. As relações de troca melhorariam em benefício dos países exportadores de produtos não industriais. Diante disso, os países periféricos não precisariam industrializar-se, para atingir o desenvolvimento econômico.

Contudo, no fim da década de 1940, percebeu-se que os principais problemas da região tendiam a agravar-se pela debilidade do poder de compra de suas exportações. Esta constatação confirmou-se com o estudo de Prebisch, que examinou a evolução dos preços de produtos agrícolas e industriais em um período de 65 anos (1880/1945).

Prebisch (1950) percebeu uma tendência nítida para a deterioração das relações de troca contra os países subdesenvolvidos: a relação preços agrícolas/preços industriais $\left(P_{a} / P_{i}\right)$, igual a unidade em 1880 (ou seja, equivalentes - 1), caiu tendencialmente para 0,687 em 1945.

Desta forma, a deterioração dos termos de troca pode ser explicada pela teoria do ciclo. $\mathrm{Na}$ fase ascendente, os preços e a renda sobem nos países desenvolvidos, o que eleva a demanda internacional de alimentos e matérias primas. Consequentemente, com preços favoráveis, os países periféricos (caso do Brasil) aumentam sua oferta. Ocorre que, no caso de produtos primários, como carnes, café e outras culturas permanentes, existe uma defasagem de resposta da oferta em alguns anos e, portanto, não é possível, obter, de imediato, todos os ganhos possíveis, devido a elevação de preços (PREBISCH, 1950).

Além disto, quando os preços começam a cair, desde o fim da fase ascendente do ciclo, os países subdesenvolvidos não conseguem reduzir de imediato sua oferta, o que deprime ainda mais os preços agrícolas na fase descendente. Nessa fase, embora a demanda externa se retraia e os preços diminuam, a oferta agrícola tende a ter uma queda menos do que proporcional, por sua rigidez, conforme demonstrado no Quadro 01 (PREBISCH, 1950, p. 59).

Quadro 01 - Deterioração dos Termos de Troca - Teoria Explicativa dos Ciclos.

\begin{tabular}{|c|c|}
\hline Fase Ascendente & Fase Descendente \\
\hline
\end{tabular}

COLÓQUIO - Revista do Desenvolvimento Regional - Faccat - Taquara/RS - v. 17, n. 1, jan./mar. 2020 


\begin{tabular}{|l|l|}
\hline $\begin{array}{l}\text { - Os preços e a renda sobem nos países desenvolvidos, } \\
\text { que eleva a demanda internacional de alimentos e } \\
\text { matérias-primas; }\end{array}$ & $\begin{array}{l}\text { - Quando os preços começam a cair, os países } \\
\text { subdesenvolvidos não conseguem reduzir de imediato } \\
\text { sua oferta - o que gera uma depressão ainda maior dos } \\
\text { preços; }\end{array}$ \\
\hline $\begin{array}{l}\text { - Com preços favoráveis, os países periféricos (caso do } \\
\text { Brasil) aumentam sua oferta; }\end{array}$ & - Demanda externa retraída e preços menores; \\
\hline - Defasagem de resposta da oferta; & - Rigidez de oferta pela defasagem; \\
\hline
\end{tabular}

Fonte: Elaborado pelos autores com base em Prebisch (1950).

De outra parte, a oferta de produtos industriais ajusta-se de imediato a demanda e aos preços. Ademais, nos países desenvolvidos, a rigidez dos salários para baixo, pela ação dos sindicatos, evita maiores reduções da demanda de produtos industriais. Pela troca desigual, essa pressão de custos é repassada a periferia (PREBISCH, 1950).

Neste sentido, a constatação da deterioração das relações de troca em detrimento dos países exportadores de produtos primários e a consequente impossibilidade de transferência dos ganhos do progresso técnico para a periferia levaram Prebisch a propor a industrialização como a única forma de desenvolvimento. A industrialização seria efetuada mediante substituição de importações, pela existência de mercados constituídos para produtos específicos, até então, importados dos países ricos. As substituições, a serem realizadas inicialmente, deveriam ser de preferência aquelas provenientes da zona do dólar, para maximizar os saldos das divisas mais escassas.

A estratégia de Prebisch (1950), para o desenvolvimento latino-americano, consistia nos seguintes pontos: a) compressão do consumo supérfluo, principalmente de produtos importados, por meio do estabelecimento de tarifas elevadas e de restrições quantitativas as importações; b) incentivo ao ingresso de capitais externos, principalmente na forma de empréstimos de governo a governo, a fim de aumentar os investimentos, sobretudo para a implantação da infraestrutura básica; c) realização de reforma agrária, para aumentar a oferta de alimentos e matérias primas agrícolas, bem como a demanda de produtos industriais, mediante a expansão do mercado interno; e d) maior participação do Estado na captação de recursos e na implantação de infraestruturas básicas, tais como energia, transportes, comunicação, entre outras.

A industrialização da América Latina não é incompatível com o desenvolvimento eficaz da produção primária. Pelo contrário, uma das condições essenciais para que o desenvolvimento da indústria possa cumprir o fim social de elevar o nível de vida, é dispor dos melhores equipamentos de maquinaria e instrumentos, e aproveitar prontamente o progresso técnico em sua regular renovação. A mecanização da agricultura implica na mesma exigência. Necessitandose de uma considerável importação de bens de capital e, também, de exportar produtos primários para consegui-la. Quanto mais ativo for o comércio exterior da América Latina, tanto maior serão as possibilidades de aumentar a produtividade de seu trabalho, mediante intensa formação de capitais. A solução não está em crescer à custa do comércio exterior e, sim, em saber extrair, de um comércio exterior cada vez maior, os elementos propulsores do desenvolvimento econômico (PREBISCH, 1950, p. 48-49). 
Neste sentido, faz-se necessário a industrialização, visto que a depreciação dos termos de troca, tendem a aumentar o benefício aos países desenvolvidos, e a alternativa para reverter tal quadro seria o processo de industrialização, via substituição de importações, ou seja, deve-se focar num modelo para dentro, com estímulo ao mercado interno e intervenção direta do Estado na economia, a fim de dar suporte a tal processo.

O elemento dinâmico não é o núcleo industrial vinculado ao mercado interno, mas sim, pelo processo de substituição de importações. A demanda preexistente passa a ser o elemento dinâmico e não as inovações no processo produtivo como nas economias avançadas (FURTADO, 2009).

Segundo Furtado (2009), o desenvolvimento do núcleo industrial interno ocorre pelo processo de substituição dos produtos anteriormente importados, que competem com os exportados, sendo as grandes preocupações dos produtores internos a fabricação de bens de consumo similares aos importados e a utilização e combinação de fatores produtivos que the deem vantagens na concorrência com os exportadores.

Em outros tempos, antes da grande depressão, os países da América Latina cresceram impulsionados "de fora para dentro" pelo aumento persistente das exportações. Nada autoriza a suposição, pelo menos por enquanto, de que este fenômeno tenha de repetir-se, com análoga intensidade, salvo em casos muito particulares. Já não se apresenta a alternativa entre seguir crescendo vigorosamente desse modo ou crescer para dentro, mediante a industrialização. Esta passou a ser o modo principal de crescer. Mas, isto não significa que a exportação primária tenha de sacrificar-se para favorecer o desenvolvimento industrial; não só porque ela subministra as divisas para adquirir as importações necessárias ao desenvolvimento econômico, mas ainda porque no valor do exportado só entra em proporção elevada à renda do solo que não implica nenhum custo coletivo. Se, por um lado, com o progresso técnico, se consegue aumentar a eficácia produtora, por outro, a industrialização e uma adequada legislação social vão elevando o nível do salário real, poder-se-á corrigir, gradualmente, o desequilíbrio de remunerações entre os centros e a periferia, sem prejuízo dessa atividade econômica essencial (PREBISCH, 1950, p. 52-53).

No sentido de contribuir com esta análise, é necessário entender melhor este aspecto. De acordo com Lewis apud Agarwala \& Singh (2010), sobre o modelo de desenvolvimento econômico com oferta ilimitada de mão de obra, a ideia principal reside em que a economia pode ser dividida em dois setores, onde um seria tradicional e arcaico, representado preponderantemente pelo setor agrícola; e o outro, moderno e dinâmico, poderia ser associado ao setor urbano-industrial. No entanto, este setor atrasado é a fonte de um excedente de mãode-obra tão importante em termos quantitativos, que equilibra os salários dos trabalhadores não qualificados ao nível da subsistência.

Assim, os países capitalistas exportam seu capital visando reduzir seus salários internos, e transferem esse capital para países subdesenvolvidos, onde remuneram salários de subsistência de acordo com as condições de vida dos países com capitalismo tardio. Aí está o processo dinâmico que os países desenvolvidos adotam, para que seus lucros continuem crescendo, de maneira ampliada. 
Para Lewis apud Agarwala \& Singh (2010), a dinâmica do crescimento econômico é dada pela (re) inversão dos lucros acumulados no setor urbano-industrial. Ou seja, a acumulação de capital, geradora do progresso econômico, depende do nível de poupança realizado pelos capitalistas. Por outro lado, numa economia subdesenvolvida, com oferta ilimitada de trabalhadores não qualificados, a produtividade marginal da força de trabalho é ínfima ou nula, e, nessas circunstâncias, o preço do trabalho corresponde ao nível de subsistência.

De modo geral, parece que o progresso técnico foi mais acentuado na indústria que na produção primária dos países da periferia. Desta forma, se os preços houvessem baixado em harmonia com a maior produtividade, tal baixa teria sido menor nos produtos primários que nos industriais, de forma que a relação de preços entre ambos fosse melhorando persistentemente, em favor dos países da periferia, conforme se acentuasse a disparidade de produtividades. Se houvesse ocorrido, esse fenômeno teria sido de profunda significação. Os países periféricos teriam aproveitado, com a mesma intensidade que os países cêntricos, a baixa dos preços dos produtos finais à indústria. Assim, os frutos do progresso técnico ter-se-iam repartido, igualmente, em todo o mundo, segundo a premissa implícita no esquema da divisão internacional do trabalho, e a América Latina não teria nenhuma vantagem econômica em sua industrialização (PREBISCH, 1950).

Em relação a tal constatação, Prebisch (1950) elenca algumas considerações sobre este processo: 1) os preços não baixaram em conformidade com o progresso técnico, pois, enquanto, por um lado, o custo tendia a baixar, em razão do aumento da produtividade, subiam, por outra parte, as remunerações dos empresários e dos fatores da produção. Quando a ascensão das remunerações foi mais intensa que a da produtividade, os preços subiram, em vez de baixar; 2) se o crescimento das remunerações, nos centros industriais e na periferia, houvesse sido proporcional ao aumento das respectivas produtividades, a relação de preços entre os produtos primários e os produtos finais da indústria, não teria sido diferente da qual e existiria se os preços houvessem baixado estritamente de acordo com a produtividade. E dada a maior produtividade da indústria, a relação de preços ter-se-ia movido em favor dos produtos primários, e; 3) como, na realidade, a relação se moveu contra os produtos primários, entre os anos setenta do século passado e os trinta do presente, é óbvio que as remunerações dos empresários e fatores da produção cresceram, nos centros, mais que o aumento da produtividade, e na periferia menos que o respectivo aumento da mesma produtividade.

Em outros termos, ao passo que os centros retiveram integralmente o fruto do progresso técnico de sua indústria, os países da periferia traspassaram-lhes uma parte do fruto de seu próprio progresso técnico (PREBISCH, 1950).

Para compreender a razão de ser deste fenômeno, Prebisch (1950) argumenta que é necessário relacioná-lo com o movimento cíclico da economia, e a forma em que se manifesta nos centros e na periferia. Pois o ciclo é a forma característica de crescer da economia capitalista e o aumento de produtividade um dos fatores primários de crescimento. Há, no processo cíclico, uma disparidade contínua entre a procura e a oferta globais de artigos de consumo terminados, nos centros cíclicos. $\mathrm{Na}$ fase crescente, a procura sobrepõe a oferta, e na minguante, ocorre o contrário. 
A razão é muito simples, pois durante a fase crescente, uma parte dos benefícios foi se transformando em aumento de salários, pela concorrência dos empresários uns com outros e, pela pressão sobre todos eles das organizações operárias. Quando, na fase minguante, o benefício tem que comprimir-se. Aquela parte que se transformou em ditos aumentos perdeu, no centro, sua fluidez, em virtude da conhecida resistência à baixa dos salários. A pressão se desloca então para a periferia com maior força que a naturalmente exercível caso não fossem rígidos os salários e os benefícios no centro, em virtude das limitações da concorrência. Assim, tanto menos possam cumprir as remunerações, no centro, tanto mais terão que fazê-lo na periferia. A desorganização característica das massas operárias na produção primária, especialmente na agricultura dos países periféricos, impede-lhes de conseguir aumentos de salários comparáveis aos alcançados nos países industriais, ou de conservá-los com a mesma efetividade. A compressão das remunerações - sejam benefícios, sejam salários - é, pois, menos difícil na periferia (PREBISCH, 1950).

Neste sentido, Prebisch (1950) destaca que a maior capacidade das massas, nos centros cíclicos, para conseguir aumentos de salários na crescente e defender seu nível na minguante, e a aptidão desses centros, em razão do papel que desempenham no processo cíclico, para deslocar a pressão cíclica para a periferia, obrigando a comprimir suas remunerações mais intensamente que nos centros, explicam por que as remunerações nestes tendem, persistentemente, a subir com mais força que nos países da periferia, segundo se torna patente na experiência da América Latina. Nisto está à chave do fenômeno pelo qual os grandes centros industriais, não apenas retêm para si o fruto da aplicação das inovações técnicas à sua própria economia, mas, ainda, estão em posição favorável para captar uma parte do que surge no progresso técnico da periferia.

Como modelo analítico de explicação, a partir de Prebisch, pai do estruturalismo da Cepal, Furtado (2009) aponta para a necessidade de modificações estruturais nas economias latinoamericanas, onde o problema do desenvolvimento é mais complexo. Não bastaria uma política voltada a utilizar a capacidade produtiva existente (ou seja, políticas econômicas do tipo quantitativo, estimulando ajustes nos valores das variáveis básicas), a eficácia somente pode ser garantida com políticas do tipo qualitativo, promovendo ajuste nas relações entre as variáveis básicas, e nisto implica modificações estruturais, na busca de estabelecer uma estratégia de modificação das estruturas dos países subdesenvolvidos.

Para remover os obstáculos estruturais ao desenvolvimento é necessário atuar sobre a oferta (para dar-Ihe maior flexibilidade) e sobre a demanda (para mudar o seu perfil). As ações sobre a oferta e sobre a demanda devem ser coordenadas. Daí a necessidade do planejamento, através de uma técnica a serviço de uma política de modificação das estruturas econômicas.

Neste contexto, o Estado aparece em destaque na obra de Furtado (2009) como um importante instrumento, cuja utilização é necessária para resolver problemas estruturais. Com efeito, o Estado é visto como esfera responsável pela coordenação e condução de políticas de planejamento que viabilizem a promoção do desenvolvimento. Portanto, como deverá ocorrer e quais são as premissas e consequências deste desenvolvimento? 
A teoria do desenvolvimento econômico trata de explicar, numa perspectiva macroeconômica, as causas e o mecanismo do aumento persistente da produtividade do fator trabalho e suas repercussões na organização da produção e na forma como se distribui e se utiliza o produto social. Essa tarefa explicativa projeta-se em dois planos. O primeiro - no qual predominam as formulações abstratas - compreende a análise do mecanismo propriamente dito do processo de crescimento, o que exige construção de modelos ou esquemas simplificados dos sistemas econômicos existentes, baseados em relações estáveis entre variáveis quantificáveis e consideradas de importância relevante. O segundo - que é o plano histórico - abrange o estudo crítico, em confronto com uma realidade dada, das categorias básicas definidas pela analise abstrata (FURTADO, 2009).

Não basta construir um modelo abstrato e elaborar a explicação do seu funcionamento. Igualmente importante é a verificação da eficácia explicativa desse modelo em confronto com uma realidade histórica. Somente essa verificação poderá indicar as limitações decorrentes do nível de abstração em que foi elaborado o modelo e sugerir as modificações a serem introduzidas para fazê-lo válido do ponto de vista de uma realidade dada (FURTADO, 2009, p. 25).

Neste sentido, Tavares $(1996 ; 2000)$ corrobora com tal análise, por meio de seu modo de pensar babilônico (sistema de pensamento aberto orientado pelas especificidades de cada realidade), ao afirmar que ao invés de se construir um único sistema lógico (abstrato, formal e generalizável) euclidiano-cartesiano, se faz recortes da realidade, focada na perspectiva histórica-estrutural, abrindo espaço para inúmeras linhas de argumentação e métodos analíticos. Isto é, reconhece a importância das especificidades históricas e estruturais, e das relações de poder econômico entre nações, para a análise do subdesenvolvimento das economias periféricas, especialmente as latino-americanas.

Tavares (1996, p.133-134) destaca que "quem é do método histórico-estrutural, pode usar elementos teóricos de várias escolas e tentar integrá-las", o que configura o aspecto da pluralidade teórica subjacente do pensamento cepalino, consagrado por Prebisch e Furtado. Desta forma, o desenvolvimento econômico é um fenômeno com uma nítida dimensão histórica. Cada economia que se desenvolve enfrenta uma série de problemas que the são específicos, se bem que muitos deles sejam comuns a outras economias contemporâneas. O complexo de recursos naturais, as correntes migratórias, a ordem institucional e o grau relativo de desenvolvimento das economias contemporâneas singularizam cada fenômeno histórico do desenvolvimento. Furtado (2009, p. 197) define subdesenvolvimento como "[...] um processo histórico autônomo, e não uma etapa pela qual tenham, necessariamente, passado as economias que já alcançaram grau superior de desenvolvimento".

O subdesenvolvimento não constitui uma etapa necessária do processo de formação das economias capitalistas. É, em si, uma situação particular, resultante da expansão dessas economias, visando a utilizar recursos naturais e de mão de obra de áreas de economia précapitalista (FURTADO, 2009).

Para Furtado (2009), isso equivale a dizer que o subdesenvolvimento não é uma fase inevitável do processo de formação das economias capitalistas, constituindo, antes, na realidade, uma "deformação". Além disto, o subdesenvolvimento é o resultado de uma conexão, surgida 
em certas condições históricas, entre um processo interno concentrador e um processo externo de dependência, onde se instalaria uma parte dos sistemas industriais dos países do centro da economia mundial, detentores de um alto grau de acumulação de capital. Este traço, com a dimensão cultural da cópia de modelos de consumo, produziria uma situação de convivência de formas heterogêneas de vida, com, de um lado, grupos sociais afluentes (onde a cópia dos novos modelos de consumo se efetiva) e, de outro, grupos sociais submetidos a níveis mínimos de subsistência, excluídos do nível de consumo das classes mais ricas.

Seguindo tal análise, Cardoso \& Faletto (1975) argumentam que o subdesenvolvimento não é necessariamente uma etapa do desenvolvimento, fazendo crítica à ideia da Europa Ocidental e dos Estados Unidos, de que o processo de desenvolvimento consistiria em levar a cabo, e inclusive reproduzir, as diversas etapas que caracterizaram as transformações sociais daqueles países, desconsiderando as variações históricas, quer dizer, as singularidades/especificidades de cada situação de subdesenvolvimento.

Os pressupostos para o novo passo da economia latino-americana são os seguintes: 1) um mercado interno suficiente para o consumo dos produtos industriais, formado desde o século passado pela integração agropecuária ou mineira ao mercado mundial; 2) uma base industrial formada lentamente nos últimos 80 anos, que compreendia indústrias leves de consumo (alimentícias, têxteis etc.) e, em certos casos, a produção de alguns bens relacionados com a economia de exportação; 3) uma abundante fonte de divisas constituída pela exploração agropecuária e mineira; 4) fortes estímulos para o crescimento econômico, especialmente em países como o Brasil e a Colômbia, graças ao fortalecimento do setor externo a partir da segunda metade da década de 1950 e; 5) a existência de uma taxa satisfatória de formação interna de capitais (CARDOSO; FALETTO, 1975).

Para Cardoso \& Faletto (1975), a análise global do desenvolvimento, não é suficiente agregar apenas ao conhecimento das condicionantes estruturais a compreensão dos fatores sociais, entendidos estes, como novas variáveis de tipo estrutural. Para adquirir significação, tal análise requer um duplo esforço de redefinição de perspectivas: por um lado, considerar em sua totalidade as condições históricas particulares - econômicas e sociais - subjacentes aos processos de desenvolvimento, no plano nacional e no plano externo; por outro, compreender, nas situações estruturais dadas, os objetivos e interesses que dão sentido, orientam ou animam o conflito entre os grupos e classes e os movimentos sociais que põem em marcha as sociedades em desenvolvimento.

Uma análise unilateral é insuficiente para explicar o curso dos acontecimentos, e assim, é reforçada a ideia de integrar a análise dos condicionantes econômicos e não econômicos, pois ainda que os graus de diferenciação da estrutura social dos diversos países da região condicionem de forma diversa o crescimento econômico, não é suficiente substituir a interpretação "econômica" do desenvolvimento por uma análise "sociológica". Falta uma análise integrada que forneça elementos para dar resposta de forma mais ampla e matizada às questões gerais sobre as possibilidades do desenvolvimento ou estagnação dos países latino-americanos, e que responda às perguntas decisivas sobre seu sentido e suas condições políticas e sociais (CARDOSO; FALETTO, 1975). 
Torna-se necessário, na perspectiva de Cardoso \& Faletto (1975), uma abordagem que não separe de forma estanque as condições econômicas, políticas e sociais e muito menos que considere apenas uma destas condições. A análise unilateral é altamente suscetível a apresentar a leitura, diagnósticos imprecisos sobre a possibilidades de desenvolvimento e, neste sentido, torna-se necessário ser substituída por uma análise integrada dos determinantes do desenvolvimento dos países, em particular, os latino-americanos.

Assim, considera-se o desenvolvimento como um resultado da interação de grupos e classes sociais que tem um modo de relação que lhes é próprio e, portanto, interesses materiais e valores distintos, cuja oposição, conciliação ou superação, dá vida ao sistema socioeconômico. A estrutura social e a política vão-se modificando na medida em que diferentes classes e grupos sociais conseguem impor seus interesses, sua força e sua dominação ao conjunto da sociedade (CARDOSO; FALETTO, 1975).

O desenvolvimento econômico é muito mais complexo, visto que é preciso que se respeitem as especificidades de cada país ou região econômica, que devido às singularidades existentes, tanto no âmbito social quanto ao estrutural, são determinantes no processo de avanço econômico, visto que não existe uma receita única para o desenvolvimento, principalmente devido às raízes históricas, geográficas, culturais, sociais, políticas, ambientais de cada país ou região. Ressalta-se que o processo de desenvolvimento que ocorreu em países como Estados Unidos, Reino Unido, Alemanha, entre outros, não se aplica aos países latinoamericanos, visto que as particularidades, especificidades e a história destes não são iguais, e por sua vez, o subdesenvolvimento (dos países da América Latina e particularmente do Brasil) não é meramente um estágio do desenvolvimento econômico, mas sim uma situação particular, devido as suas condições e construções históricas, sociais, políticas, econômicas e ambientais.

Deste modo, devem ser respeitadas as especificidades do processo de desenvolvimento, visando estabelecer suas características, e assim, conforme argumentado pelos pensadores ao longo desta reflexão teórica, elencar as trajetórias distintas que levaram o Brasil ao estágio de desenvolvimento (subdesenvolvimento) no século XX.

\section{Processo de (sub) desenvolvimento brasileiro}

No Brasil, historicamente, a primeira experiência de industrialização impulsionada pelo Estado ocorreu na década de 1950. Antes, o papel do Estado na promoção do desenvolvimento industrial foi praticamente insignificante até fins da década de 1920, e bastante limitado dos anos 1930 a princípios dos 1950. No primeiro período, o crescimento da produção industrial estava atrelado ao desempenho do setor agrícola-exportador. O mercado interno de produtos manufaturados dependia da renda gerada no setor exportador, por sua vez dependente da demanda externa por produtos brasileiros. A partir da Primeira Guerra Mundial, o Estado começou a estimular o desenvolvimento de algumas indústrias específicas, mas não o desenvolvimento industrial em geral. Os incentivos e subsídios eram concedidos a empresas individuais e não a setores ou indústrias, não eram sistemáticos, e foram pouco eficazes (SUZIGAN, 1988). 
No período a partir da década de 1930, a ação do Estado em defesa do setor agrícolaexportador em crise (mais especificamente em relação a produção de café) ajudou indiretamente o desenvolvimento industrial. As exportações cafeeiras geraram divisas que proporcionaram investimentos no processo de industrialização. A demanda de produtos manufaturados passou a crescer primordialmente em função da renda gerada nas atividades ligadas ao mercado interno, e o nível da renda foi mantido elevado por políticas macroeconômicas expansionistas em defesa do setor exportador. A proteção a indústria foi dada por desvalorizações cambiais e restrições não-tarifárias as importações motivadas pela crise cambial. Com isso a industrialização avançou, substituindo importações de bens de consumo não duráveis e de alguns bens intermediários. Mais tarde, na década de 1940, o Estado passou a investir diretamente em algumas indústrias de bens intermediários (siderurgia, mineração, energia, etc.) e na produção de motores pesados.

Foi a partir de 1950, no entanto, que o Estado passou a desempenhar um papel mais ativo na estruturação do setor industrial. Em primeiro lugar, na articulação entre o capital privado nacional, o capital estrangeiro e o próprio Estado. Neste contexto, foi considerada importante a definição de uma estratégia geral de desenvolvimento a qual levaram a estruturação dos planos nacionais de desenvolvimento, com políticas e planejamento em longo prazo e o estabelecimento de metas industriais, com grupos de empresários específicos de cada setor. Em segundo lugar, a proteção ao mercado interno foi substancialmente aumentada. Essa proteção era dada por uma tarifa aduaneira, altamente protecionista, e pela política cambial, através do controle do mercado de câmbio e de taxas de câmbio diferenciadas segundo o sistema de prioridades. Em terceiro lugar, o Estado passou a fomentar o desenvolvimento industrial, após a criação do Banco Nacional de Desenvolvimento Econômico (BNDE). E, por fim, o Estado ampliou a sua participação direta através de investimentos na indústria de base (siderurgia, petroquímica e de mineração) e realizou pesados investimentos em infraestrutura econômica (energia e transportes).

Como resultado, a estrutura industrial avançou no sentido de incorporar segmentos da indústria pesada, da indústria de bens de consumo duráveis e da indústria de bens de capital, substituindo importações de insumos básicos, máquinas e equipamentos, automóveis, eletrodomésticos, etc. Essa estrutura foi à base sobre a qual se apoiou o rápido crescimento da produção industrial na primeira fase do ciclo expansivo brasileiro, mais propriamente definido como período do "milagre brasileiro".

Para Furtado (2009, p. 165), a economia brasileira se configurou como um caso de economia híbrida que não se comportou em todas as circunstâncias como uma estrutura précapitalista. A massa de salários no setor ligado ao comércio internacional teria sido suficiente para o crescimento de uma faixa monetária no sistema econômico que resultou em mudanças nos hábitos de consumo, a partir da introdução de artigos manufaturados de origem estrangeira.

A diversificação no consumo acarretou consequências relevantes para o desenvolvimento da economia. Com o crescimento da importância da renda monetária, ocorreu o aumento da pressão sobre o balanço de pagamentos nos períodos de declínio dos preços internacionais, gerando condições favoráveis para a criação de atividades ligadas ao comércio interno. 
Assim, a cafeicultura dava origem a um fluxo de lucros além dos salários. Lucros estes investidos na própria atividade cafeicultora que provocavam a absorção da economia de subsistência e financiavam a migração europeia, promovendo expansão do setor monetário na economia. A atividade cafeicultora apresentava necessidades elevadas de manufaturas, o que originou um mercado de produtos manufaturados, que justificou posteriormente a implantação de um núcleo industrial, que permitiu a modificação da estrutura econômica (FURTADO, 2009, p. 167).

O desenvolvimento no Brasil ocorreu de fora para dentro, a constituição do núcleo industrial deu-se a partir da formação da demanda por manufaturas, satisfeita com importações, que no momento de indisponibilidade de oferta externa imprimia dinâmica à economia pelo lado da procura, possibilitando a introdução de indústrias produtoras de artigos de consumo em geral como tecidos, alimentos elaborados, determinando o processo de substituição de importações.

A economia constituiu-se de três setores: a) voltado para as atividades de subsistência, onde o fluxo monetário é reduzido; b) comércio exterior, e; c) produtos manufaturados para o mercado interno.

O caso brasileiro apresentava uma condição econômica subdesenvolvida complexa, com uma estrutura que ia além da coexistência de empresas estrangeiras e sistema pré-capitalista. 0 elemento dinâmico não passa a ser o núcleo industrial vinculado ao mercado interno, o desenvolvimento do núcleo industrial ainda é pela substituição de importações, sendo a demanda preexistente o elemento dinâmico e não as inovações no processo produtivo como nas economias avançadas, contudo o processo de crescimento não seria interrompido pela estagnação da capacidade de importar (FURTADO, 2009).

Deste modo, a CEPAL e seus pensadores estimularam o processo de industrialização brasileira, via processo de substituição de importações, visando o estímulo e a proteção da indústria nascente.

Embora a ação do Estado entre meados dos anos 1960 e fins da década de 1970 tenha sido decisiva para integrar a estrutura industrial e consolidar o processo de industrialização, as políticas implementadas apresentaram deficiências e lacunas em termos de política industrial que contribuíram para criar uma mentalidade protecionista, agravar o atraso tecnológico e manter a indústria com baixos níveis de eficiência e competitividade. De fato, as políticas de industrialização implementadas desde os anos 1950 foram predominantemente defensivas e se caracterizaram por um protecionismo exagerado e permanente. Juntamente com a política cambial, essas políticas favoreceram taxas de rentabilidade mais elevadas no mercado interno relativamente à exportação, criando assim uma tendência à produção para o mercado interno. O resultado foi o desenvolvimento de uma indústria com elevado grau de ineficiência, e por isso mesmo não competitiva interna e internacionalmente, e com pouca criatividade em termos tecnológicos.

Essa ineficiência e baixa competitividade da indústria brasileira resultaram da ausência de uma estratégia de desenvolvimento científico e tecnológico como parte compensatória das políticas de industrialização implementadas. Ou seja, a estratégia utilizada foi a de blindar a economia, reservando o mercado para produtores locais, inclusive empresas estrangeiras. 
Assim, de acordo com Prebisch (1950), o subdesenvolvimento dos países periféricos (realidade brasileira), derivava de fatores externos e internos. Os fatores externos decorriam da dependência dos países periféricos aos países centrais. Essa dependência resultava na deterioração dos termos de troca: os países dependiam, na maior parte dos casos, do dinamismo de apenas um produto de exportação e do mercado estrangeiro. O crescimento dos países periféricos mostrava-se dependente de: a) do crescimento da renda externa e das cotações dos produtos agrícolas em mercados manipulados (dependência comercial); b) das importações de máquinas e de outros produtos industriais essenciais, cujos preços eram fixados por oligopólios e que tinham tendência para se elevar (dependência tecnológica); c) do volume das importações dos países estrangeiros, e, portanto, de sua política econômico-financeira (dependência financeira). Já os fatores internos decorriam da concentração fundiária, da reduzida dimensão do mercado interno e da elevada taxa de crescimento demográfico, incrementada por uma indústria ineficiente e más condições de infraestrutura de transportes, energia, comercialização, etc.

Enfim, o esgotamento do modelo de substituição de importações, levou o governo brasileiro a reformular sua política econômica, que culminou em um processo de abertura comercial da economia brasileira.

No entanto, a partir dos anos 1980 (conhecida "década perdida"), o Estado não apenas deixou de orientar como retardou o desenvolvimento industrial. A indefinição de uma política industrial, o drástico corte nos investimentos públicos e privados (forte endividamento externo) e a redução no esforço de incorporação de progresso técnico (pesquisa e desenvolvimento, implantação de setores de tecnologia de ponta, formação de recursos humanos) tornam muito mais sério para a sociedade brasileira o desafio de tornar-se competitiva a nível internacional e garantir sua inserção na economia mundial.

Deste modo, tal entrave, concomitantemente ligado a um processo de instabilidade econômica mundial, trouxe ao país um período extremamente difícil, com altos níveis de endividamento externo, ou seja, com incapacidade de investimento (pesquisa e desenvolvimento), além de um período de estagnação da economia brasileira, proporcionado por um período altamente inflacionário, e ainda combinado com um ambiente protecionista em relação às indústrias brasileiras, que, encontrava-se em níveis ineficientes e não competitivos.

$\mathrm{Na}$ década de 1990, com a abertura comercial brasileira, houve um processo de reestruturação interna, que a levou a uma adequação frente a forte competitividade internacional por produtos manufaturados. Neste período, também se destaca o combate a inflação, com o lançamento do Plano Real, em 1994, que controlou o processo inflacionário instaurado, proporcionando estabilidade econômica ao país, possibilitando uma política econômica mais voltada ao desenvolvimento, com retorno de investimentos, tanto público quanto privado, e, inclusive, com o retorno de expectativas em relação a um planejamento de longo prazo.

A teoria da dependência da América Latina, desenvolvida por Cardoso \& Faletto (1975), é galgada na hipótese de que as economias subdesenvolvidas só cresceriam se houvesse uma 
transformação nas sociedades e nos sistemas econômicos, para romper os laços de dependência colonial ou de poder (em relação aos centros, detentores do capital).

No entanto, os investimentos estrangeiros não são obstáculos ao desenvolvimento das economias dos países periféricos ou subordinados; pelo contrário, era a sua alavanca - eram eles que dinamizavam os países dependentes. Assim, é possível a acumulação industrial, apesar da manutenção dos laços de dependência em relação ao capital estrangeiro e da exclusão de uma numerosa população de diversos setores sociais (CARDOSO; FALETTO, 1975).

A condição de região subdesenvolvida no quadro da economia internacional, em relação aos países da América Latina, era de que os projetos de desenvolvimento econômico em voga nesses países não se referiam à realidade: "O que contribuiu para o êxito das economias nacionais nos países de 'desenvolvimento originário' foi o fato de que estas se consolidassem simultaneamente com a expansão do mercado mundial, de maneira que tais países passaram a ocupar as principais posições no sistema de dominação internacional que se estabelecia" (CARDOSO; FALETTO, 1975, p. 170).

Diante disso, Cardoso \& Faletto (1975) queriam demonstrar que não havia possibilidades das economias dos países latino-americanos se desenvolverem de maneira autônoma dissociada às economias desenvolvidas. Esta dinâmica é chamada de dependente-associado.

Enfim, o Brasil apresentou uma trajetória distinta de desenvolvimento nas últimas décadas. Passou por momentos de expansão econômica, principalmente nas décadas de 1960 e 1970, chegando a momentos de restrição econômica, nas décadas de 1980 a 1990, influenciados por um forte endividamento externo e desequilíbrio financeiro, acentuados por um processo inflacionário latente. Tal trajetória demonstra a complexidade da formulação de políticas e de planejamento público no Brasil, em um ambiente altamente volátil da economia internacional, na busca do desenvolvimento. Portanto, o Brasil teve como modelo para a superação de seu "subdesenvolvimento" a industrialização por substituição de importações (PSI), originário do pensamento econômico histórico-estrutural da escola de desenvolvimento cepalino.

\section{Considerações finais}

O estudo tratou de investigar as raízes históricas que os principais pensadores, trouxeram para contribuir com a análise do processo de desenvolvimento ou subdesenvolvimento da América Latina, em particular o Brasil, visando proporcionar uma visão crítica, através de apresentação de razões econômicas e não econômicas, que influenciaram e deram rumo à evolução do país, no âmbito da mensuração de suas realidades e especificidades distintas do seu desenvolvimento, em relação, ou se comparado aos países já desenvolvidos, ditos capitalistas.

Desde os anos 1950 até fins da década de 1970 o Estado desempenhou um papel ativo na estruturação e consolidação do setor industrial no Brasil. Nos anos 1950, a partir da definição de uma estratégia de desenvolvimento econômico e do estabelecimento de metas industriais, o Estado articulou o papel do capital privado nacional, do capital estrangeiro e do próprio Estado, e criou um sistema de proteção ao mercado interno, fomentando o desenvolvimento industrial e o investimento pesado em infraestrutura e indústrias de base. 
Entre fins dos anos 1960 e meados dos anos 1970, após as reformas institucionais de meados da década de 1960, houve a implementação de políticas macroeconômicas expansionistas, com criação de um sistema de promoção de exportações de manufaturados. Neste período o desenvolvimento do sistema financeiro e o subsídio à formação de capital industrial aceleraram a industrialização. Na segunda metade da década de 1970, o planejamento de um novo ciclo de investimentos públicos e privados nas indústrias de insumos básicos e bens de capital, ainda que a custa de maior endividamento externo, permitiu integrar a estrutura da indústria e consolidar a industrialização do país.

Entretanto, os níveis elevados e o caráter permanente da proteção ao mercado interno, bem como o insuficiente desenvolvimento científico e tecnológico, levaram a uma indústria ineficiente, tecnologicamente atrasada e com baixa competitividade a nível internacional.

A crise da década de 1980 foi marcada pela aceleração inflacionária, que afetou principalmente os segmentos de menor poder aquisitivo, e pelas elevadas taxas de desemprego. A estabilização dos preços e modernização do parque produtivo, que se destacou nos anos 1990 (abertura comercial e estabilização pela criação do Plano Real, em 1994), revelou que, apesar de atrasadas frente aos movimentos internacionais, tais conjunturas proporcionaram uma recuperação efetiva do crescimento econômico brasileiro, propiciando assim, inclusive, melhoras nas condições sociais do país.

Por sua vez, cabe ainda salientar que tais pensadores, principalmente em relação aos autores da teoria histórica-estruturalista, da qual emerge a CEPAL, lideraram a maior corrente de pensamento desenvolvimentista latino-americana. Ou seja, foram os principais precursores deste arcabouço teórico sobre as dinâmicas do desenvolvimento econômico, e por fim, influenciaram de forma direta as teorias econômicas posteriores, mais particularmente após a década de 1960.

Dito isto, para finalizar, tais pensadores como Prebisch, Furtado, Tavares, Cardoso \& Faletto e Lewis, formaram a base teórica para o desenvolvimento de políticas públicas do Estado. Esta base teórica teve como visão à superação dos entraves, principalmente de cunhos estruturais e sociais. Assim estimularam à promulgação do desenvolvimento econômico da América Latina e especificamente o Brasil, tomando por base o estímulo à indústria nascente e o incentivo ao consumo interno, ou seja, o chamado desenvolvimento para "dentro".

\section{Referências bibliográficas}

AGARWALA, A. \& SINGH, S (org). Economia do subdesenvolvimento. 2. ed. Rio de Janeiro: Contraponto, 2010.

ANJOS \& FARAH. Economia Brasileira. Coleção Gestão Empresarial. 43-55, 2005.

CARDOSO, F. M.; FALETO, E. Dependência e desenvolvimento da América Latina. Rio de Janeiro: Zahar, 1975.

CASTRO, Antônio. B. Agricultura e desenvolvimento no Brasil. Ensaios sobre a economia brasileira. 3. ed. Rio de Janeiro: Forense Universitária, 1977. 
FURTADO, Celso. Desenvolvimento e subdesenvolvimento. 5. ed. Rio de Janeiro: Contraponto, 2009.

. Teoria Política do desenvolvimento. 10. ed. São Paulo: Paz e Terra, 2000.

LEWIS, Arthur. O desenvolvimento econômico com oferta ilimitada de mão-de-obra. In:

AGARWALA, A. N. \& SING, S. P. A economia do subdesenvolvimento. São Paulo: Forense, 1969. (Publicado pela 1a a vez em 1954 pela The Manchester School).

LEWIS, Arthur. The roots of development theory. In: Handbook of development Economics, vol. I., 1979.

NURKSE, Ragnar. Problema da formação de capital em países subdesenvolvidos. Rio de Janeiro: Civilização Brasileira, 1957.

PREBISCH, Raul. O desenvolvimento da América Latina e seus principais problemas. Revista Brasileira de Economia, Rio de Janeiro, n³, p. 47-111, set. 1950.

SERRA, José. Ciclos e mudanças estruturais na economia brasileira do pós-guerra. In. BELUZZO, Luiz Gonzaga M. \& COUTINHO, Renata. (orgs.). Desenvolvimento capitalista no Brasil. 4. ed. Campinas: Brasiliense, 1998.

SUZIGAN, W. Estado e industrialização no Brasil. Revista de economia política, São Paulo, n. 8, v. 4, p. 5-16, out./dez., 1988.

TAVARES, M. C. “Entrevista”. In: BIDERMAN, C., COZAC, L. F. L., REGO, J. M. (1996) (orgs.)

Conversas com Economistas Brasileiros. São Paulo: Editora 34, 1996.

. "Subdesenvolvimento, Dominação e Luta de Classes". In: TAVARES, M. C. (2000) (org.) Celso Furtado e o Brasil. São Paulo: Fundação Perseu Abramo, 2000. 